Article

\title{
Transforming the Dynamics of Climate Politics in Japan: Business' Response to Securitization
}

\author{
Takahiro Yamada \\ Graduate School of Environmental Studies, Nagoya University, Japan; E-Mail: yamada.takahiro@k.mbox.nagoya-u.ac.jp
}

Submitted: 28 April 2021 | Accepted: 19 July 2021 | Published: 22 October 2021

\begin{abstract}
In 2020, Japan suddenly changed course and made carbon neutrality its intermediate target. In an attempt to understand this drastic policy change, this article analyzes the effects of climate security discourses on the perception of the Japanese business community, which holds the pivotal position in Japan's climate policy. It particularly focuses on the effect of securitization on the source-impact asymmetry, one of the intrinsic features identified as a major obstacle to effective climate governance. From this standpoint, the article measures the extent to which the issue of climate change has been securitized in Japan, and also the extent to which the Japanese business community has come to share the securitizers' sense of exigency. In so doing, this article employs the text-mining method called KH Coder to analyze relevant government documents as well as statements issued by Keidanren (also known as Japan Business Federation). The analysis shows that the Ministry of the Environment together with other governmental actors has collectively securitized the issue within the context of Japanese society, but that its impact on industry has been indirect, pointing to the complexity of its causal impact.
\end{abstract}

\section{Keywords}

business community; climate policy; environmental politics; Japan; securitization

Issue

This article is part of the issue "Climate Change and Security" edited by Yasuko Kameyama (National Institute for Environmental Studies, Japan) and Yukari Takamura (University of Tokyo, Japan).

(C) 2021 by the author; licensee Cogitatio (Lisbon, Portugal). This article is licensed under a Creative Commons Attribution 4.0 International License (CC BY).

\section{Introduction}

In 2019, Japan received two ignominious Fossil of the Day awards from the Climate Action Network for refusing to phase out coal-fired power generation and also for not upgrading its 2030 target of a $26 \%$ carbon emission cut from the 2013 level. Indeed, ever since the 2011 Fukushima nuclear disaster, Japan has been building new coal-fired power plants to make up for the decommissioned nuclear power plants rather than expanding renewable energies (Schumacher, 2017). In 2018, Japan's dependence on thermal power reached $85.5 \%$ of its total power supply with coal power taking up a third of that portion (Agency for Natural Resources and Energy, 2021). Needless to say, this excessive dependence on coal firing has become a major obstacle to Japan's upgrading of its emission reduction targets. Yet, in the fall of 2020, the government abruptly announced its new 2050 target of carbon neutrality, followed by the announcement of a target aiming for a $46 \%$ reduction in emissions by 2030 in April 2021. In the following month, the government revised the Act on the Promotion of Global Warming Countermeasures to give the new 2050 decarbonization target the legal foundation that it needed (“Kaisei-chikyuondankataisakusuisin-ho," 2021).

The primary aim of this article is to understand this policy change by examining whether a sense of urgency shared among Japanese policymakers and the business community became the driving force for this change. For an analytical framework to guide our research, this article draws on the "securitization" literature developed by the Copenhagen School in international relations with a view to adapting the concept to the context of climate policy. How will we know when the securitization 
of climate change is successful? What features of the climate issue would work against it? Which governmental actors have engaged in a securitizing act in Japan? Has such securitization moderated the effects of those features militating against successful securitization? Has the business community changed its attitude toward the mitigation of climate change as a result of that? In answering these questions, this article shall make full use of a text-mining method developed for social research to analyze the contents of both the government's official documents and the statements issued by Keidanren (also known as Japan Business Federation) with regards to climate issues.

The following caveats are, however, in order. First, the text-mining method used in this article can only provide us with a broad picture of overall tendencies with ample room for different interpretations. Consequently, the inference that will be drawn from the data will be necessarily subjective. In order to address this deficiency inherent in such a text-mining method, however, the author shall supplement the analysis to the extent possible with available qualitative data to make the inference as plausible as it can be. Second, even if the text-mining method does not directly reveal the causal impact of securitization on the perception of a target actor, which is, in the case of this article, the Japanese business community, it does not necessarily mean that securitization has had no impact. It simply means that the causal link between the securitization and the actor's attitudinal change is more complex than can be captured by this quantitative method. It is therefore more important to see empirically if there has been an attitudinal change in the target actor, and to find out what the attitudinal change has been associated with to make an inference from the available data. With this in mind, let us now take a look at the concept of securitization.

\section{Challenges in the Securitization of Climate Change}

\subsection{Applying the Concept of Securitization to Climate Change}

Environmental issues are one of the first non-military areas to which the concept of security was applied by practitioners and scholars alike (Brundtland, 1987; Homer-Dixon, 1994; Palme, 1982). In applying the concept to environment issues, their intention was to point out that overburdened eco-systems would seriously undermine nations' security in the traditional sense of the word based on a statist "threat-defense" logic. This article, however, will follow in the footsteps of the Copenhagen School of security studies originally developed by Barry Buzan, Ole Wæver, and Jaap de Wilde, and will feature an alternative, more expansive view that the concept of security has characteristics, which are common to different sectors, going beyond the traditional logic (Buzan et al., 1998). The reason for taking this theoretical stance is not because the inquiries into the effect of securitization on traditional security actors are unimportant, but rather it is because the objective of this article is to find out empirically whether the securitization of climate issues has had any effects on industry's perception toward the issue of climate in Japan. From this standpoint, therefore, this article sees a security problem as emerging in any situation where the existence of something or someone is seriously being threatened. In the environmental sector, the earth system or civilizations can be a security issue (for instance, any threat to the continued existence of species; Buzan et al., 1998, p. 23). By extension, the problem of "climate security" exists whenever climate change endangers the global ecosystem, the safety of coastal and riparian areas, agricultural production, public health, and/or social stability (Gleditsch, 1998; Kameyama \& Ono, 2021; Levy, 1995; McDonald, 2013; Trombetta, 2008). The "securitization" of climate therefore refers to a process whereby the perception of an existential threat to some of these objects comes to be shared by important members of a collectivity (Buzan et al., 1998, pp. 29-31). As such, the process generally involves two steps. First, some authoritative actor claims that there is an existential threat to some objects (a securitizing act). Second, a "significant audience" accepts this discourse as a legitimate claim (Buzan et al., 1998, p. 25).

This interaction between the securitizing actor and the audience is readily applicable to climate security. Given the importance of science, an epistemic community composed of climatologists should be the most likely candidate for an effective securitizing actor in this field (Buzan et al., 1998, pp. 71-73; Haas, 1990, 1992, 2007, 2016). Once the scientific claim is confirmed, however, other actors such as governmental actors and NGOs are expected to join in as securitizing agents as well. Who is the most significant audience for the securitization of climate, then? It is without question industry, because it is the largest contributor to the emission of $\mathrm{CO}_{2}$, and as such should be the most important audience for, as well as the most powerful "veto actor" against securitization (Buzan et al., 1998, pp. 75-79).

What needs to be revised in the original formulation of securitization, however, is the criteria for "successful" securitization. The original formulation associates successful securitization with the adoption of extraordinary emergency measures "outside the normal bounds of political procedure" (Buzan et al., 1998, p. 24). Yet, it is clear that this will not apply to climate change, because any decision to address climate security cannot be transpolitical in nature. We should consider securitization to be successful as long as it "transforms the way of dealing with" the problem instead (Trombetta, 2011, p. 137). That is, as long as the securitization of climate urges a country to set an ambitious emission reduction target as well as to reformulate its energy policy to meet such a target, the securitization of climate should be regarded as successful, even if its outcome does not include a transpolitical and/or trans-legal regulatory response. 


\subsection{Two Types of Asymmetry as Constraints on Climate Securitization}

Even so, securitization is not easy. Different factors bear upon the outcome (Balzacq, 2011, pp. 7-8; Salter, 2011, pp. 122-126). Here two intrinsic features of climate change that may work against successful securitization shall be discussed. One is what shall be referred to as source-impact asymmetry. This feature is concerned with the discrepancy between the location where the impacts of climate change are felt and the location of its sources. This asymmetry is indeed a common feature shared by other global environmental issues (Buzan et al., 1998, pp. 84-91). In the case of climate change, countries in the Global North have generally been the sources of the problem, while countries in the Global South are the ones which feel most of its impacts in the form of floods, droughts, or forest fires (Yamada, 2017). This asymmetry thus increases the cost of mitigation relative to its benefits for industrialized economies.

Another impediment is what shall be referred to as scale-identity asymmetry. That is, there is a mismatch between the scale of the problem and the identity of actors. The scale of the climate issue is inherently systemic in terms of its sources as well as its impacts regardless of their uneven distribution within the system. Yet, the identity of states that make up the system is not yet sufficiently global; actors rarely regard the welfare of the system as their own (Wendt, 1999). This selfregarding identity of states is likely to create a dynamic of rivalry among states, and as such states will be reluctant to come to grips with a threat of a global nature in fear that doing so will put them at a disadvantage vis-à-vis others especially in commercial competition. In other words, the scale factor matters for an effective response to a global environmental challenge (Buzan et al., 1998).

The Japanese experience seems to bear these claims out rather well, because until recently Japan has been most reluctant to set ambitious $\mathrm{CO}_{2}$ emission reduction targets. Just before the Paris Conference of 2015, the Japanese government proposed an emission cut of only $26 \%$ from the 2013 level by 2030, and it announced a cut of only $80 \%$ by 2050 in the following year (Kotsubo, 2016). The $26 \%$ emission reduction target in particular did not seem ambitious enough in light of the fact that the EU was already planning to reduce its emissions by at least $40 \%$ from the 1990 level in part by consolidating multi-level approval procedures for renewable energy development (Oberthür, 2019; Schumacher, 2019). As unambitious as these Japanese targets may be, Keidanren still criticized the government on behalf of coal-dependent industries for setting such demanding targets (Japan Business Federation, 2016, pp. 7-8). Moreover, it has also fought tooth and nail against any hint of introducing carbon pricing, be it emissions trading or a carbon tax (Ohta, 2016, pp. 231-258). This business community's deep-seated resistance has been driven in part by Japanese electric utilities' need to meet spikes in electricity demand during heat waves, and also in part by the hitherto lack of progress in sustainable finance with Japan's major banks being firmly committed to coal-fired power plants, both domestically and internationally (Schumacher et al., 2020). For their part, the Ministry of Economy, Trade and Industry (METI) and the Liberal Democratic Party have also consistently endorsed industry's lethargic position (Sekine \& Sakurai, 2018). Protected by this "iron triangle," therefore, industry's lack of enthusiasm toward decarbonization has come to set the tone for the country's Basic Energy Plans. According to the most recent Basic Energy Plan at the time of this writing, Japan should aim, in the supply of electricity, for a $26 \%$ share in coal-fired power, a 20 to $22 \%$ share in nuclear power, and a 22 to $24 \%$ share in renewable energy by 2030 (Sakurai et al., 2020). Arguably, therefore, Japan's climate policy has been effectually subordinated to its coal-dependent energy policy.

In light of this context, in the section below, the following questions should be addressed. First, to what degree has the climate issue been securitized and by whom? If multiple governmental actors have been involved in the securitization, what commonalities do these actors have? Has the Paris Agreement affected the way in which the climate issue has been securitized? Second, how has securitization affected the two asymmetries discussed above? While we can readily speculate that climate securitization will drive home to the audience that Japan is a victim as much as a culprit of climate change, thus somewhat rectifying the sourceimpact asymmetry, it would be unrealistic to assume that securitization will suddenly change the identity of states from "rivals" to "friends" even in the presence of a common global threat. As such, we should primarily focus on the first asymmetry in our following analysis. Third and finally, we should ask whether climate securitization has transformed the view of the business community and if it has, to what extent and how? The most straightforward impact of securitization on industry would be that industry would come to share the securitizers' view of climate security, resulting in the moderation of industry's resistance to setting ambitious emission reduction targets and hence in the acceptance of the government's about-face on climate policy. Has that been the case? Let us explore this below, but first methodology should be discussed.

\section{Analyzing the Government's Climate Security Discourses and Their Impact on the Japanese Business Community}

\subsection{Methodology}

Let us briefly discuss the analytical methods used in this article. In order to analyze the discourses and hence the perception of relevant actors, the text-mining method called KH Coder (hereafter Coder) will be applied to the official documents of these actors (Higuchi, 2017). This 
method has allowed the author to do the following: first, to measure the frequency of words used in the text, second, to create "co-occurrence networks" among dyads of words used in each sentence, and third to measure the level of co-occurrence between specific words.

Here is how the data are collected. First, the documents, which are available in $\mathrm{html}$ or pdf formats on the actors' official sites, have been divided into two groupings, using 2015, the year when the Paris Agreement was concluded, as a threshold. The reason for this division is because the Paris Agreement has required all of its parties to report their adaptation measures, thus enabling them to reflect on their own climate risks. Second, only those sentences containing words related to climate change have been selected for analysis, and the Coder's frequency function has been used to measure the frequency of word appearance. Here it is assumed that the more frequent the appearance of the words associated with "threat and security" (e.g., "emergency," "threat to life," and "death") is in the texts, the level of securitization will be higher. Moreover, it is also assumed that the level of securitization will be higher still if these words are accompanied by such adjectives as "serious" and "urgent."

Third, "co-occurrence" networks containing both "nodes" and "edges" that connect these nodes are created for each group of texts by using the Coder's co-occurrence function. The threshold of word appearance for nodes is set according to the volume of sentences in the examined text so that there will be around 150 nodes for each map. Similarly, the threshold for connectivity is set to include around 600 edges so as to keep the number of co-occurrence clusters within 10 . The networks above this threshold are thus grouped into clusters shown in different colors. It is assumed here that the nodes that are connected by edges have intimate relationships, and that the more edges there are, the greater the intimacy of their relationships will be.

Fourth, the Coder's word association function has been used to measure the relative proportions of co-occurrences between specific words, which are deemed to be important in deciphering the actors' perceptions on key topics. It is assumed here that the greater the proportion of co-occurrences in a given dyad is, the relationship of the dyad will be stronger than that of other dyads. Lastly, the Coder's keyword in context function has been used to examine how the tightly linked words are actually used in the text.

\subsection{Securitization by the Ministry of Environment}

Let us start with the Ministry of the Environment (MOE), which is the most likely domestic candidate for a securitizing actor. Figures 1 and 2 show the co-occurrence networks for the Kankyo hakusho (White Papers on the Environment; MOE, 2009, 2010, 2011, 2012, 2013, 2014, 2015, 2016, 2017, 2018, 2019, 2020a) being divided into two periods: Period 1 (2009-2014) and Period 2
(2015-2020), respectively. The network nodes that are shown in Figure 1 contain words that appear 85 times and above, and the threshold of 600 "edges" is used for creating clusters. In Figure 2, words used 120 times and above appear as nodes, and the links containing 750 edges and above appear as co-occurrence clusters.

What does the comparison of these two periods tell us? First and foremost, the data indicate that the usage of words connoting existential threats has substantially increased, with the frequency of words coded as "threat and security" jumping from 69 times in Period 1 to 99 times in Period 2, and the frequency of words coded as "risk" similarly jumping from 65 times to 167 times. It implies that Japan is now increasingly being portrayed as a victim of climate change. Accordingly, Figure 1 indicates that the "adaptation" node (toward the very left in red in the middle range) for Period 1 is quite small in size, and also not connected to any concrete policies, whereas Figure 2 shows that the "adaptation" node (toward the bottom in light blue) for Period 2 is more pronounced, and also connected to words such as "planning," "local governments," and "adaptation policy" as well as to "impacts," indicating that adaptation has become a real policy issue. If one looks more closely at the 2020 white paper, for instance, it provides concrete data on the number of deaths caused by heat strokes "closely connected" with climate change, reaching 1581 and 1224 deaths in 2018 and 2019, respectively, and also refers to the testing of the "heat-stroke warning alert" system developed jointly by the MOE and the Japan Meteorological Agency in the Kanto region to promote the adoption of preventive measures among citizens (MOE, 2020a, pp. 90-91). In the same document, the MOE also discusses the importance of promoting renewable energies such as electric vehicles that can be used as alternative sources of electricity in the event of a large-scale blackout resulting from a storm (MOE, 2020a, p. 37).

Has this change in self-perception affected Japan's attitude toward mitigation, then? In this connection, it is important to see that the word "de-carbonization" appears only in Period 2, although as a small node (toward the top in green in Figure 2); in Period 1 the word "low carbon" (toward the bottom on the right in mustard in Figure 1) appears instead. This is rather significant, because it suggests that the MOE has begun to emphasize the importance of bringing down the nation's carbon emission to zero only since 2015. Moreover, this analysis clearly shows that the MOE has placed a premium on the introduction and promotion of renewable energies (on the right in red in Figure 2 back-to-back with the "low carbon" cluster) in achieving either low or zero carbon emissions. The overall picture as to where the MOE stands on the issue of climate security is thus clear; faced with greater climate risks, Japan should aim for a low-carbon or decarbonized society by shifting to renewable energies as soon as possible.

These analytical results are corroborated by the statement made by Environmental Minister Shinjiro Koizumi 


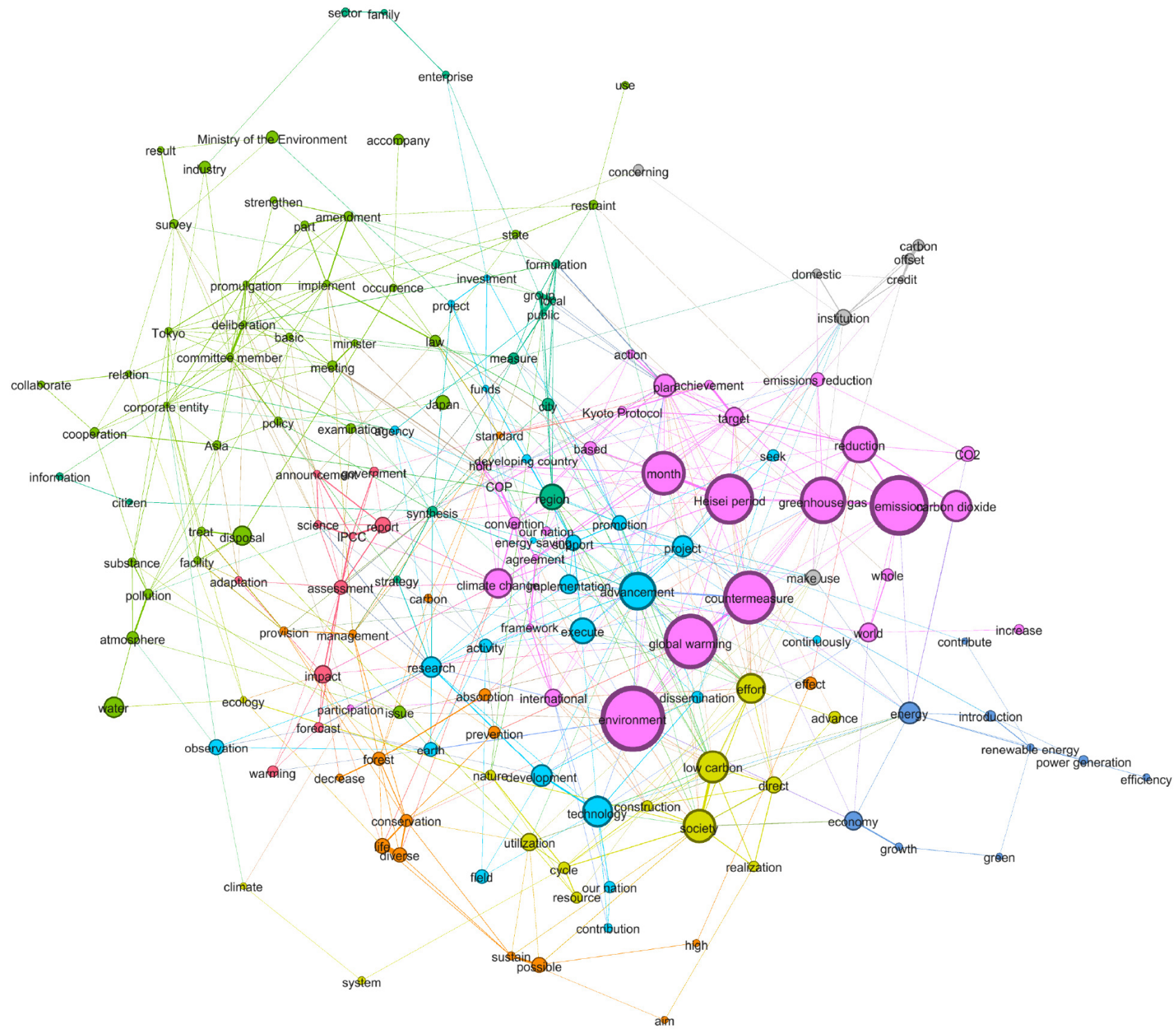

Figure 1. The discourse map of the MOE for Period 1.

at a news conference held in connection with the 2020 White Paper on the Environment on June 12, 2020:

This year for the first time, we the Ministry of the Environment have made it explicit in the White Paper that we now regard the issue of climate change as the climate crisis.... It has been pointed out that, from now on, global warming will increase the risks of rain storm disasters and heat waves even further, and we think that we are currently facing this very crisis....As such, we are planning to share this sense of crisis with many other players in an attempt to facilitate the transformation of our society....And in order to turn this crisis into an opportunity, we would like to collaborate to an even greater extent than before with other relevant ministries, local governments, businesses and our citizens in order to promote the redesigning of our economy and society in the post Covid-19 period by making three tran- sitions, namely transitions to decarbonization, a circulation economy, and a decentralized society....The reason why we the Ministry of the Environment are currently seeking and enhancing collaboration with the Ministry of Defense over renewable energies is precisely because we share the belief that such collaboration will contribute to those things (the independence and survival of our nation) and also that this climate crisis is a national security issue for our country. (translated by the author; MOE, 2020)

\subsection{The Formation of a Coalition of Securitizing Actors Within the Government}

How have other ministries responded to the climate risks? Have they come to share the MOE's view of climate security? Here let us analyze the official documents that have been co-authored by multiple ministries entitled The Synthesis Reports on the Monitoring, 


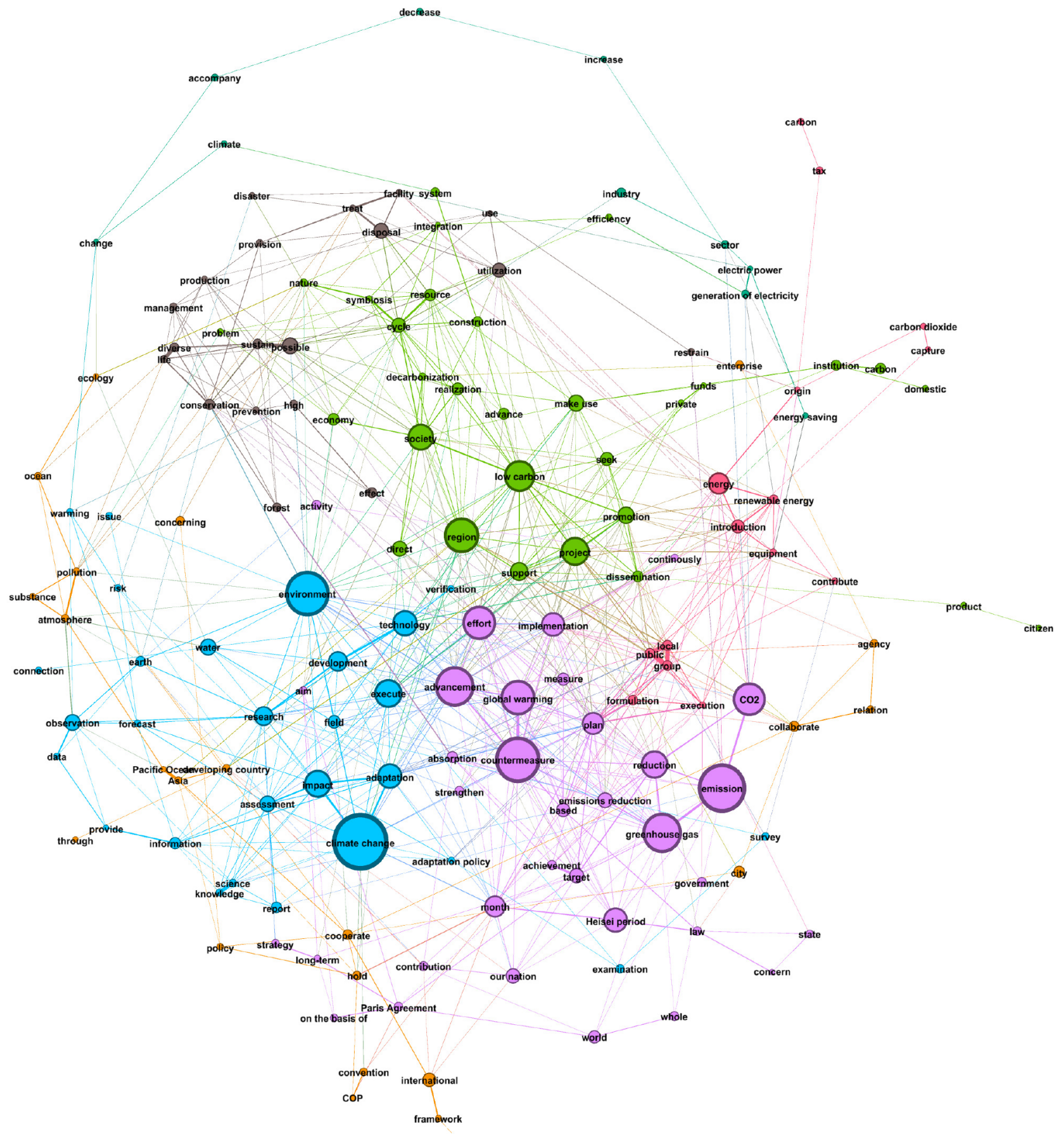

Figure 2. The discourse map of the MOE for Period 2.

Forecast and Assessment of Climate Change (synthesis report below) to see what their collective discourses suggest. Two synthesis reports (Ministry of Education, Culture, Sports, Science and Technology et al., 2009, 2012) were published in Period 1, and were co-authored by the Japan Meteorological Agency, the Ministry of Education, Culture, Sports, Science and Technology and the MOE. In Period 2, so far only one synthesis report
(MOE et al., 2018) has been published, but two more ministries, namely the Ministry of Land, Infrastructure and Transport and the Ministry of Agriculture, Forestry and Fisheries, have joined the authorship.

Figure 3 shows co-occurrence networks from the synthesis reports from Period 1. All the texts containing a total of 1394 sentences have been coded and the words used 30 times and above appear as nodes, 


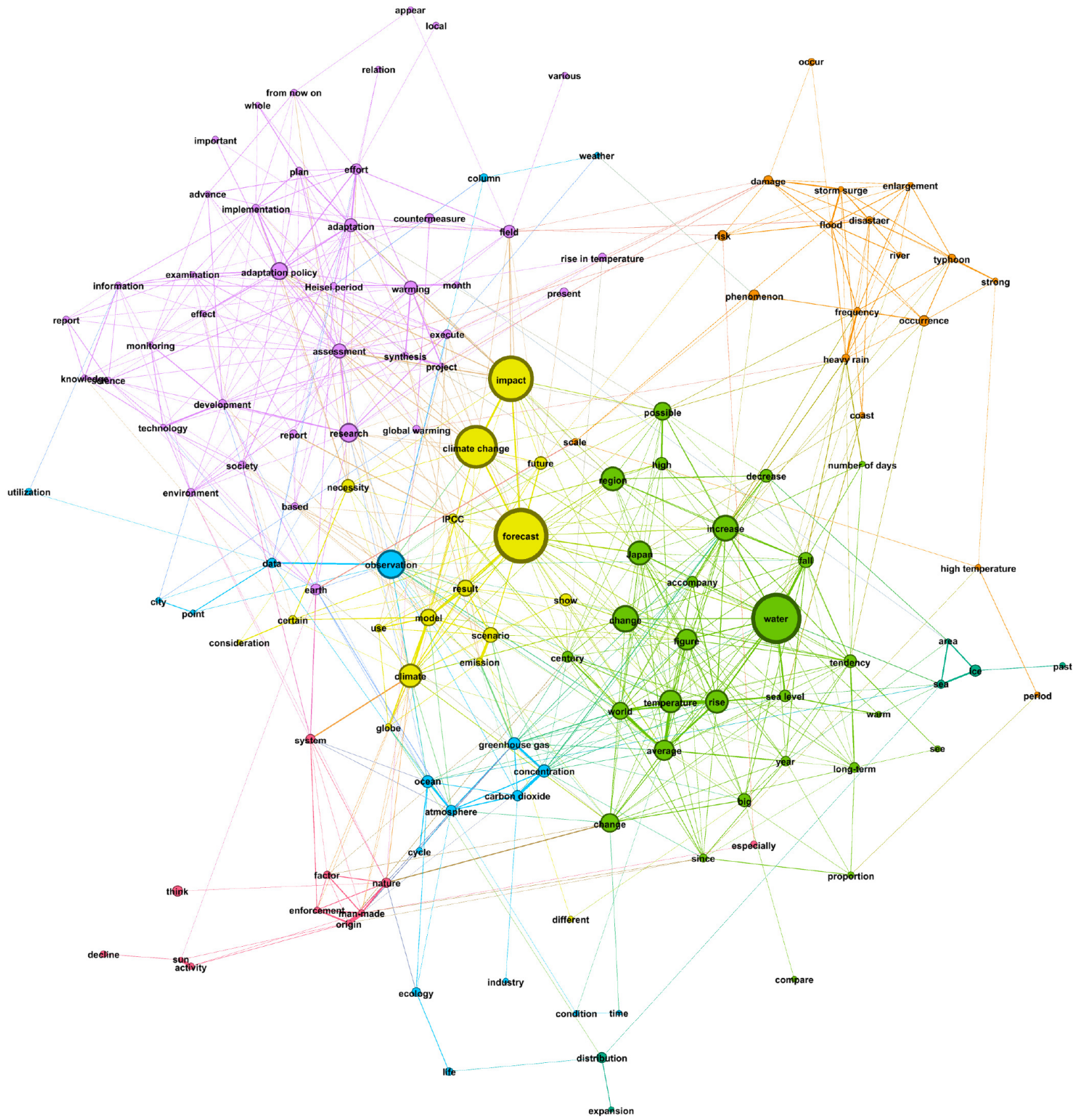

Figure 3. The discourse map of a bureaucratic coalition for Period 1.

and 700 "edges" and above as co-occurrence clusters. Similarly, Figure 4 shows co-occurrence networks for the synthesis report in Period 2, which contains a total of 1027 sentences. Here the words used 25 times and above appear as nodes, and 600 "edges" and above as cooccurrence clusters.

First of all, the most striking difference between the two periods is that the report in Period 2 makes more references to the social and economic impacts of climate change, as "climate change" seems strongly linked to "agriculture" and "disaster" (in the lower right quadrant in purple in Figure 4); by comparison, "impact" (a notice- able node near the center in mustard in Figure 3 ) is not directly linked to "disaster" (a small node in the upper right quadrant in orange) in Period 1. Moreover, in the report for Period 2 more pages are given to the impacts of climate change on Japan itself; a total of 60 pages are on the potential impacts of climate change, of which 56 are on Japan referring to such impacts as the degradation of rice grains, decreasing fish stocks, and the increasing number of landslides. This tendency is also clearly indicated by an increase in the number of specific types of disasters being mentioned such as typhoons and floods (the upper right quadrant in orange in Figure 4). The term 


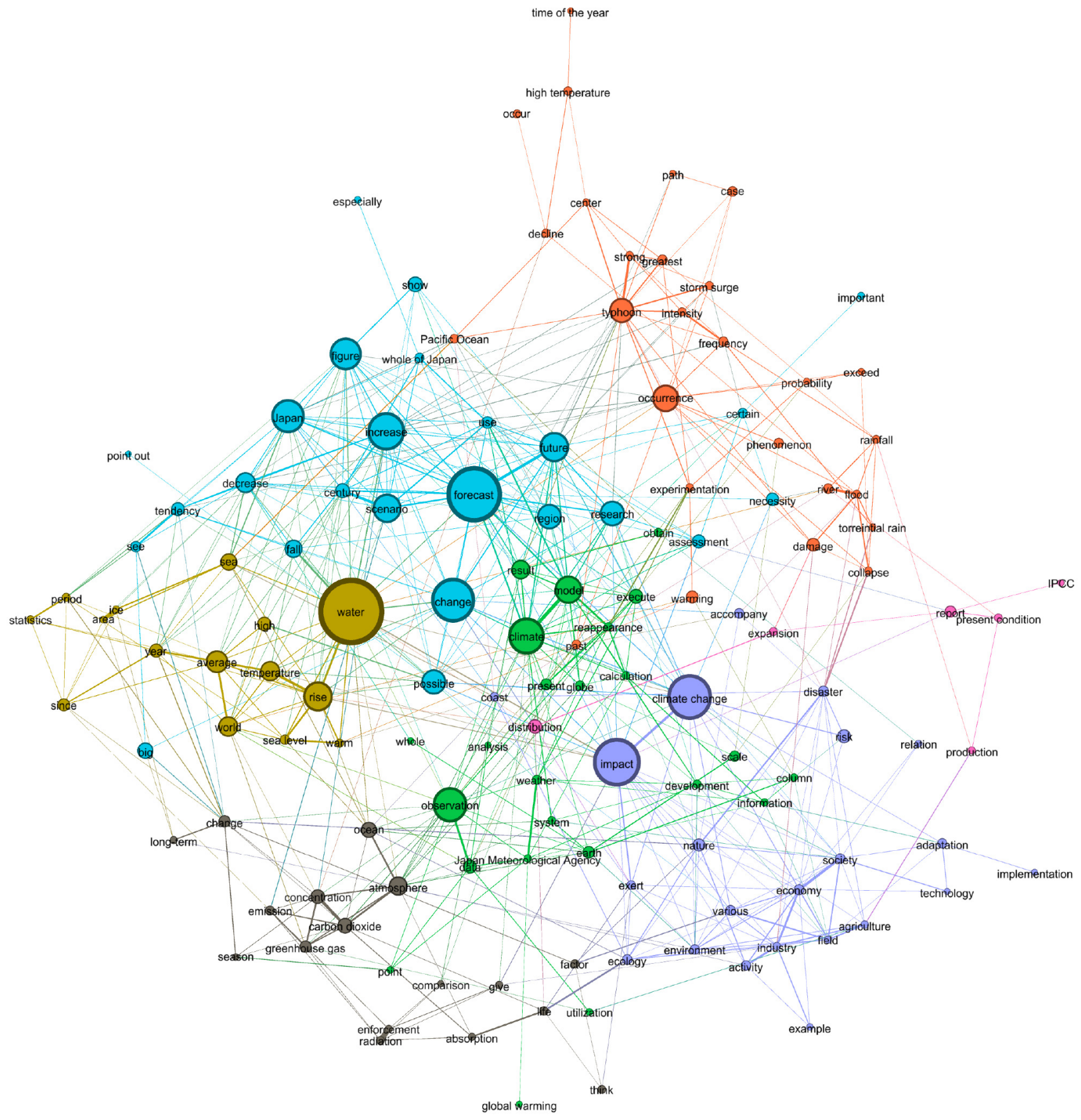

Figure 4. The discourse map of an expanded bureaucratic coalition for Period 2.

"typhoon," for instance, appears 128 times in Period 2, whereas it appears only 59 times in Period 1. Equally importantly, the link between these disasters and such adjectives as "strong" or "maximum level" seems strong in Period 2; 46\% of the sentences containing the word "typhoon" also contain the term "maximum level." In this context, it is interesting to note that the report discusses fatalities as well as the destruction of houses resulting from landslides within the context of linear rain bands and typhoons (MOE et al., 2018, p. 98). This tendency to emphasize the serious impacts of climate change is also shown in the increasing number of references being made to its security threats and risks. The number of sen- tences containing words coded as "threats and security" or "risk" has increased in Period 2 from 17 to 35, and 37 to 66 , respectively. In this connection, it is worth mentioning that the 2018 report cites droughts and floods affecting agricultural production as a typical case of a climate risk for Japan (MOE et al., 2018, p. 114). Also, interestingly enough, this report provides the data indicating a long-term trend in the rise of deaths caused by heat strokes as well as a strong correlation between those deaths and the number of days marking highs exceeding $30^{\circ} \mathrm{C}$ (MOE et al., 2018, p. 107).

In sum, from the analysis above, one can therefore infer that a coalition of governmental actors including 
domestically oriented powerful ministries such as the Ministry of Land, Infrastructure and Transport and the Ministry of Agriculture, Forestry and Fisheries has been the driver for the securitization process in Japan. The only difference between the MOE's white papers and the synthesis report in Period 2 is that the latter does not contain many references to de-carbonization itself. This is, however, to be expected, given that the synthesis report was written precisely for the purpose of sharing information on climate risks within the government. Arguably, then, it has successfully produced the collective knowledge that Japan is as much a victim of climate change as its culprit.

\subsection{The Effect of Securitization on the Business Community}

How has this securitization process affected the perception of the Japanese business community? As discussed earlier, Keidanren has been one of the most vocal veto actors, refusing to accept even the $80 \%$ emissions cut that the Japanese government had committed itself to.

Figure 5 shows co-occurrence networks that have emerged from the coding of the two most recent Keidanren documents on the issue of climate (Japan Business Federation, 2020a, 2020b). A total of 240 sentences in these two documents have been coded and

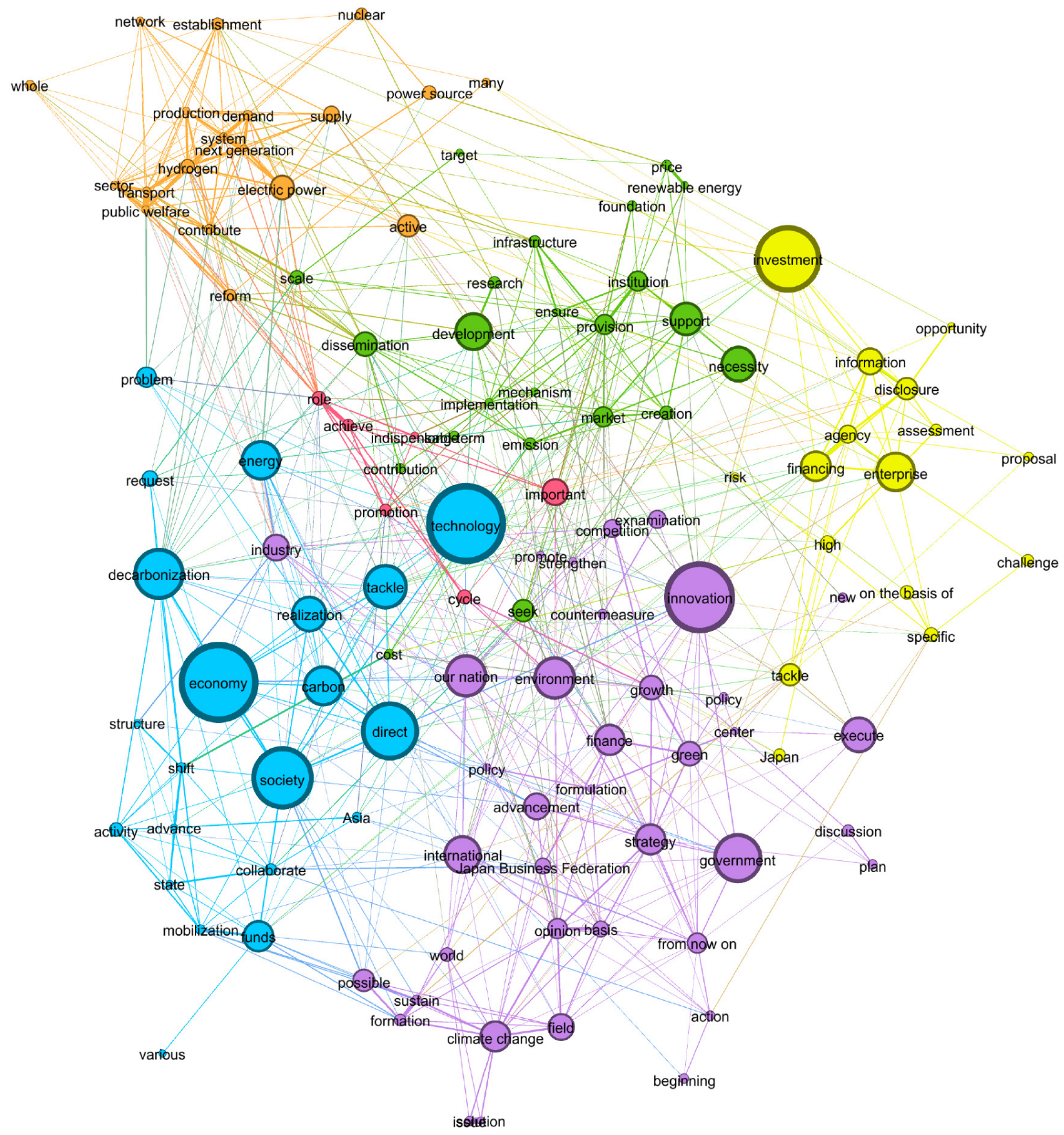

Figure 5. The discourse map of keidanren regarding climate issues. 
the words used five times and above appear as nodes while 700 "edges" and above appear as co-occurrence clusters. One of the most interesting features regarding Keidanren's discourses is that unlike the government discourses analyzed above, almost no security-related terms show up in these documents, even though the term "climate crisis" comes up once in one of them. The use of the term "decarbonization," on the other hand, is more salient in these documents. This raises an interesting question. Where does Keidanren's interest in "decarbonization" come from, if it is not generated by the existential threat from climate change?

Regardless of its origin, however, if businesses aspire to achieve decarbonization, they obviously need to call their dependence on thermal power into question. Yet, it is strange that the term "thermal power" does not even constitute a node in this discourse map. Only "nuclear power" shows up as a node (toward the very top in orange), while the term "renewable energy" is closely linked to "price" (in the upper right quadrant in green), suggesting that renewables are too costly for industry. In contrast to "renewable energy," the node of "technology" is fairly prominent (near the center in blue), and well connected to the node of "decarbonization" (toward the left also in blue); nearly a third of the sentences containing "decarbonization" have co-occurrences with the word "technology." Furthermore, the link between "finance" and "innovation" (in the lower right quadrant in purple) also seems rather strong with almost $60 \%$ of the sentences containing the word "finance" having co-occurrences with the word "innovation." This suggests that the business community deems sustainable finance crucial for technological innovation, a view also shared increasingly by the Japanese financial community committed to promoting environmental, social, and corporate governance investments (Schumacher et al., 2020). This mapping therefore suggests that the Japanese business community is less interested in altering the composition of Japan's basic energy structure than in promoting technological innovation as a way to achieve decarbonization. The Keidanren's Challenge Zero initiative whereby 137 corporate entities carry out projects aimed at developing "green technology" (Japan Business Federation, 2020a) is a case in point. More interesting still is the presence of a strong link among the terms "finance," "innovation," "government," "growth," and "strategy" (also in the lower right quadrant in purple), because this connectivity clearly suggests that the business community expects the government to play an active role in promoting innovation as part of a national growth strategy.

What can we infer from these findings? First, there is no evidence that the Japanese business community has accepted the characterization of climate change as an existential crisis. In this sense, the government's securitizing effort has had no direct impact on the perception of the business community. This is indeed a significant finding of this study because it suggests that there is a clear divide between those governmental actors, which have become more aware of the existential threat of climate change, and industry which does not seem so concerned with the security risks associated with climate change. Second, the business community has nevertheless decided to take on the challenge of carbon neutrality. This represents a fundamental change on the part of the business community in light of the fact that Keidanren was opposed even to the $80 \%$ emission cut target. This therefore raises an intriguing question as to what has motivated the business community to accept the target of decarbonization in the absence of recognition of climate risks. Third, in connection with this question, we can speculate that the driver for this about-face may have stemmed from industry's fear of losing international competitiveness in the emerging "green economy" as well as from the financial sector's aversion to "transitional climate risks" associated with its investment in traditional fossil fuel power generation (Schumacher et al., 2020). The former concern in particular has been reflected in Keidanren's expectation for the government to be actively involved in promoting the innovation for decarbonization. Contrary to the expectation posited at the outset, therefore, the scale-identity asymmetry has worked to promote mitigation rather than constraining it, precisely because it has encouraged inter-state commercial rivalry. Although, due to a lack of space, the METI is not discussed in this article, the analysis of the Energy White Paper of 2020 published by the METI's Agency for Natural Resources and Energy has revealed similar patterns: no appearance of words associated with "risks and threats" and the frequent use of the word "innovation" in association with "green finance" as well as "strategy" (Agency for Natural Resources and Energy, 2020). The only difference is that the term "low carbon" rather than "decarbonization" is more frequently used in the Agency for Natural Resources and Energy document.

Although the analysis above does not allow us to attribute industry's attitudinal change directly to the securitization of climate change, one should be cautious in drawing the conclusion that the securitization of climate change has not affected the business community's decision to endorse the target of carbon neutrality, because industry is, generally, not monolithic particularly in regards to the issue of climate with some industrial sectors being more predisposed than others to behave in the anticipation of regulatory changes. Given the fact that the coalition of governmental actors have been pushing for more stringent regulatory measures to address the climate security threat, it is highly probable that some forward-looking industries such as the auto industry, and the financial sector have become the driving forces for change. The former is increasingly being caught up in the global technological race for electric vehicles, and the latter has the substantial financial risks of being associated with carbon-intensive energy in the would-be decarbonized economy. Put differently, the relationship between the existential threat of climate change and the perceptive and attitudinal change of 
industry could be more complex and indirect than this text-mining analysis may suggest.

It is therefore plausible to argue that the coalition of securitizing government actors led by the MOE has been able to create an anticipatory regulatory environment for a decarbonized economy to persuade both the business community and the current administration to adopt a more stringent emission reduction target. In fact, Environmental Minister Koizumi reached out to Keidanren and successfully negotiated an agreement in September 2020 between the ministry and the business federation that defined their respective roles in Japan's effort to meet the challenges of the climate crisis. According to this agreement, Keidanren promised to: (1) vigorously promote the Challenge Zero initiative and collaborate with the MOE with respect to Task Force on Climate-Related Financial Disclosures, ScienceBased Targets, and Renewable Energy 100\%, aimed at disclosures of climate-related information, setting emission reduction targets in compliance with the Paris Agreement, and the full use of renewables, respectively, toward the realization of a decarbonated society; and also (2) to promote sustainable finance and environmental, social, and corporate governance investment, all in an effort to "redesign our economy and society into a more sustainable and resilient one as we face the twin crises of Covid-19 and climate" (MOE, 2020b). With this agreement in hand, the reappointed environmental minister, Shinjiro Koizumi, strongly urged the newly elected prime minister, Yoshihide Suga, to accept the 2050 target of decarbonization. Prime Minister Suga then moved to persuade Minister of Economy, Trade and Industry Hiroshi Kajiyama to accept the target of decarbonization after rounds of consultation with the vice-ministers of both the MOE and the METI, and most importantly with Chairman of Keidanren Hiroaki Nakanishi. Much to the surprise of the METI, Nakanishi responded to the prime minister's request, albeit in his capacity as a member of the Council of Economic Advisors, with his proposal of a "green growth" strategy aimed at carbon neutrality by 2050 (Shimizu, 2020). This led the way for the prime minister to announce the 2050 target of decarbonization as part of his inauguration speech in the fall of 2020.

Even this cursory process-tracing showing how Prime Minister Suga reached his decision, therefore, lends support to the observation that the pervasiveness of the sense of climate crisis within the government has precipitated industry's acquiescence to decarbonization. The unanimous approval of the Declaration of Climate Emergency in both Houses of the Diet in November 2020 (Okimoto, 2020) is indeed a testimony to how pervasive this sense of crisis was becoming within the government at the time.

\section{Conclusion}

This article has attempted to tailor the concept of securitization associated with the Copenhagen School to the context of climate policy. In so doing, it has emphasized the "performative" nature of a securitization process leading to a redefinition of priorities characterizing the conventional political order. For climate change, the redefinition of priorities has meant the primacy of climate policy over the conventional energy policy catering to the needs of energy-intensive industries. Moreover, our discussion has focused on two intrinsic features of the climate issue that could militate against successful securitization, namely the source-impact asymmetry, and the scale-identity asymmetry. The former was expected to weaken the incentive of industrialized countries to address the global threat of climate change, and the latter was expected to make it difficult for countries in general to regard the welfare of the global community as their own, thus hampering the mitigation of climate change. Indeed, both of these asymmetries were found to be at work in Japan at least prior to the Paris Agreement, because Japan clearly prioritized the stable supply of low-cost energy from the extensive use of coal-fire power over the development of the renewable energy sources indispensable for effective mitigation.

Against this theoretical and empirical backdrop, the article has set out to see by using a text-mining method how the source-impact asymmetry has been moderated since the Paris Agreement, and how this moderation has affected the Japanese government's decision to upgrade its mitigation policy as well as industry's decision to commit itself to decarbonization. The analysis of industry's perception was considered crucial in this inquiry because business would be the most likely candidate for a veto actor in this political game. Therefore, in light of the fact that Japan made a policy about-face and announced the target of achieving carbon neutrality by 2050 , it was initially assumed that the sourceimpact asymmetry had been lessened to a sufficient level to allow Japan to see climate change as an existential threat to its own security, and that the business community also shared this view. Contrary to this assumption, however, the text-mining analysis performed in this article did not show that industry shared this view, while it did show that the key governmental actors such as the MOE, Ministry of Land, Infrastructure and Transport, and Ministry of Agriculture, Forestry and Fisheries saw the country as becoming increasingly threatened by climate change. This has therefore led to a conundrum as to why industry has accepted the carbon neutrality target without recognizing the existential threat of climate change. This has indeed highlighted the complexity of the causal link between climate security and industry's acceptance of decarbonization.

This article has thus made the following three contributions to the discussion on the issue of climate and security. First, it has modified the theory of securitization to make it more applicable to the issue of climate change by clarifying the expected effects of the securitization of climate. Second, it has isolated two types of asymmetries that may work against addressing climate security and 
has then empirically shown through the use of a textmining method how one of them, namely the sourceimpact asymmetry, has, after the conclusion of the Paris Agreement, been sufficiently moderated in Japan to germinate the sense of "climate crisis." Third and finally, the analysis of industry's discourses on climate has generated a new theoretical and empirical puzzle regarding the relationship between securitization and mitigation with regards to the business community. The last point, which has, admittedly, not been fully addressed in this article, poses an interesting theoretical question with regards to the effect of securitization, because it suggests that the second type of asymmetry, namely the scale-identity asymmetry, has worked, not as an impediment to the global effort to address the issue of climate, but as a driver for such an effort. A further qualitative study is obviously needed to see how this reversal of its function has occurred. Such a study should open up the "black-box" of the business community's decisionmaking process that has led to its acceptance of the government's decarbonization target.

\section{Acknowledgments}

This research has been conducted as part of the Fluctuation-Led Governance Transformation Project funded by the Japan Society for the Promotion of Science, to which the author is deeply grateful. It has also been made possible by the operating research grants provided by Nagoya University. The author would also like to thank Haruki Kondo for his assiduous research assistance in collecting and coding the documents analyzed in this article, as well as anonymous reviewers for their extremely constructive comments.

\section{Conflict of Interests}

The author declares no conflict of interests.

\section{References}

Agency for Natural Resources and Energy. (2020). Enerugii hakusho [Energy white paper].

Agency for Natural Resources and Energy. (2021). Nihon no enerugii 2020 [Energy in Japan 2020] [Pamphlet]. https://www.enecho.meti.go.jp/about/ pamphlet/pdf/energy_in_japan2020.pdf

Balzacq, T. (2011). A theory of securitization: Origins, core assumptions, and variants. In T. Balzacq (Ed.), Securitization theory: How security problems emerge and dissolve (pp. 1-30). Routledge.

Brundtland, G. H. (1987). Our common future. Oxford University Press.

Buzan, B., Wæver, O., \& de Wilde, J. (1998). Security: A new framework for analysis. Lynne Rienner.

Gleditsch, N. P. (1998). Armed conflict and the environment: A critique of the literature. Journal of Peace Research, 35(3), 381-400.
Haas, P. M. (1990). Saving the Mediterranean: The politics of international environmental cooperation. Columbia University Press.

Haas, P. M. (1992). Introduction: Epistemic communities and international policy coordination. International Organization, 46(1), 1-37.

Haas, P. M. (2007). Epistemic communities. In D. Bodansky, J. Brunnée, \& E. Hey (Eds.), Oxford handbook of international environmental law (pp. 791-806). Oxford University Press.

Haas, P. M. (2016). Epistemic communities, constructivism, and international environmental politics. Routledge.

Higuchi, K. (2017). A two-step approach to quantitative content analysis: $\mathrm{KH}$ Coder tutorial using anne of green gables (part II). Ritsumeikan Social Science Review, 53(1), 137-147. http://www.ritsumei.ac.jp/ file.jsp?id=346128

Homer-Dixon, T. (1994). Environmental scarcities and violent conflict: Evidence from cases. International Security, 19(1), 17-36. https://homerdixon.com/ evidence-from-cases-full-article

Japan Business Federation. (2016). Pari-kyotei o humaeta kongo no chikyuondanka-taisaku ni kansuru teigen [A proposal for future global warming countermeasures based on the Paris Agreement]. https:// www.keidanren.or.jp/policy/2016/094_honbun.pdf

Japan Business Federation. (2020a). 2050-nen kaabonnyuutoraru (society 5.0 with carbon neutral) jitsugen ni mukete-keizaikai no ketsui to akushon [Toward realizing carbon neutrality by 2050 (society 5.0 with carbon neutral): Determination and actions of the business community]. https://www.keidanren.or.jp/ policy/2020/123_honbun.pdf

Japan Business Federation. (2020b). Kikohendobunya no sasutenaburu fainansu ni kansuru kihontekina kangaekata to kongo no akushon [Basic approach to sustainable finance on climate change and concrete actions]. https://www.keidanren.or.jp/policy/2020/ 094_honbun.pdf

Kaisei-chikyuondankataisakusuisin-ho towa, sokusinkuiki de saiseiene kasoku [What does the revised act of the promotion of global warming countermeasures entail? Acceleration of renewable energies by designating promotion zones]. (2021, May 27). Nihon Keizai Shimbun. https://www.nikkei.com/ article/DGXZQOUA265W00W1A520C2000000

Kameyama, Y., \& Ono, K. (2021). The development of climate security discourse in Japan. Sustainable Science, 16, 271-281. https://doi.org/10.1007/s11625020-00863-1

Kotsubo, Y. (2016, May 13). 2050-nen madeni 8-warisakugen, kettei, seihu ga Onshitsugasutaisakukeikaku [The government decided on its Global Warming Prevention Plan to aim for an $80 \%$ cut by 2050]. Asahi Shimbun. https://www.asahi. com/articles/ASJ5F35KZJ5FULBJ003.html

Levy, M. A. (1995). Is the environment a national security 
issue? International Security, 20(2), 35-62. https:// doi.org/10.2307/2539228

McDonald, M. (2013). Discourses of climate security. Political Geography, 33, 42-51. https://doi.org/ 10.1016/j.polgeo.2013.01.002

Ministry of Education, Culture, Sports, Science and Technology, Japan Meteorological Agency, \& MOE. (2009). Ondanka no kansoku, yosoku oyobi eikyohyoka togo repooto "nihon no kikohendo to sono eikyo" [Synthesis report on observations, forecasts, and assessments of climate change: "Climate change in Japan and its impact]. https://www.env.go.jp/ earth/ondanka/rep091009/full.pdf

Ministry of Education, Culture, Sports, Science and Technology, Japan Meteorological Agency, \& MOE. (2012). Ondanka no kansoku, yosoku oyobi eikyohyoka togo repooto "nihon no kikohendo to sono eikyo" [Synthesis report on observations, forecasts, and assessments of climate change: "Climate change in Japan and its impact]. http://www.env.go.jp/ earth/ondanka/rep130412/report_full.pdf

MOE. (2009). Kankyo hakusho [White paper on the environment].

MOE. (2010). Kankyo hakusho [White paper on the environment].

MOE. (2011). Kankyo hakusho [White paper on the environment].

MOE. (2012). Kankyo hakusho [White paper on the environment].

MOE. (2013). Kankyo hakusho [White paper on the environment].

MOE. (2014). Kankyo hakusho [White paper on the environment].

MOE. (2015). Kankyo hakusho [White paper on the environment].

MOE. (2016). Kankyo hakusho [White paper on the environment].

MOE. (2017). Kankyo hakusho [White paper on the environment].

MOE. (2018). Kankyo hakusho [White paper on the environment].

MOE. (2019). Kankyo hakusho [White paper on the environment].

MOE. (2020a). Kankyo hakusho [White paper on the environment].

MOE. (2020b). Kankyo to seicho no kojunnkanni muketa koronago no keizaishakai no saisekkei (redesign): Datsutanso-shakai jitsugen ni muketa KankyoshoKeidanren no renkei ni kansuru goi [To redesign our post-Corona economy and society toward a virtuous growth-and-environment circle: The agreement on the collaboration between the Ministry of the Environment and Keidanren toward the realization of a decarbonated society]. https://www.keidanren.or. jp/policy/2020/084.pdf

MOE. (2020, June 12). Koizumi daijin kishakaikenroku [Record of press conference with Minister Koizumi] [Press Release]. https://www.env.go.jp/ annai/kaiken/r2/0612.html

MOE, Ministry of Education, Culture, Sports, Science and Technology, Ministry of Agriculture, Forestry and Fisheries, Ministry of Land, Infrastructure and Transport, \& Japan Meteorological Agency. (2018). Ondanka no kansoku, yosoku oyobi eikyohyoka togo repooto "nihon no kikohendo to sono eikyo" [Synthesis report on observations, forecasts, and assessments of climate change: "Climate change in Japan and its impact"]. https://www.keidanren.or. jp/policy/2020/123_honbun.pdf

Oberthür, S. (2019). Hard or soft governance? The EU's climate and energy policy framework for 2030. Politics and Governance, 7(1), 17-27. https://www. cogitatiopress.com/politicsandgovernance/article/ view/1796

Ohta, H. (2016). Shuyokoku no kankyo to enerugii o meguru hikakuseiji: Jizokukanoshakai eno sentaku [The environmental and energy politics of major states from a comparative perspective: Making a choice for a sustainable society]. Toshindo.

Okimoto, K. (2020, November 26). Kikohijojitai-sengen, shusan-ryouin deno kaketsu ga imisuru mittsu no koto [Three things that the passage of the Climate Emergency Declaration means]. Sustainable Brands Japan. https://www.sustainablebrands.jp/news/jp/ detail/1199448_1501.html

Palme, O. (1982). Common security: A programme for disarmament: The report of the independent commission on disarmament and security Issues under the chairmanship of Olof Palme. Pan Books.

Sakurai, R., Itou, H., \& Ishii, T. (2020, October 22). Kaitei de onshitsugasusakugen wa, Ondankataisakukeikaku, Enerugii Kihonkeikaku [Revisions of the Global Warming Prevention Plan and the Basic Energy Plan underway. How will that affect ghgs emission reduction targets]. Asahi Shimbun. https://www. asahi.com/articles/DA3S14667847.html

Salter, M. B. (2011). When securitization fails: The hard case of counter-terrorism programs. In T. Balzacq (Ed.), Securitization theory: How security problems emerge and dissolve (pp. 116-132). Routledge.

Schumacher, K. (2017). Large-scale renewable energy project barriers: Environmental impact assessment streamlining efforts in Japan and the EU. Environmental Impact Assessment Review, 65, 100-110. https:// doi.org/10.1016/j.eiar.2017.05.001

Schumacher, K. (2019). Approval procedures for largescale renewable energy installations: Comparison of national legal frameworks in Japan, New Zealand, the EU and the US. Energy Policy, 129, 139-152. https:// doi.org/10.1016/j.enpol.2019.02.013

Schumacher, K., Chenet, H., \& Volz, U. (2020). Sustainable finance in Japan. Journal of Sustainable Finance and Investment, 10(2), 213-246. https://doi.org/ 10.1080/20430795.2020.1735219

Sekine, S., \& Sakurai, R. (2018, April 28). Genpatsu "juuyona dengen" toshuu, saiene wa "shuryokuden- 
gen mezasu," Enerugii Kihonkeikaku kosshian [The Basic Energy Plan. Its draft outline continues to see nuclear power generation as an "important power source," but expects renewable energies to be "primary power sources]. Asahi Shimbun. https://www. asahi.com/articles/DA3S13471704.html

Shimizu, M. (2020, December 8). Koizumi kankyosho ga mita shusho ketsudan: "Datsutanso" eno rubikon [Environment Minister Koizumi witnessed how the prime minister made the decision: Crossing the Rubicon over to "decarbonization"]. Nihon Keizai Shimbun. https://www.nikkei.com/article/ DGXZQOGH071NQ0X01C20A2000000/

Trombetta, M. J. (2008). Environmental security and cli- mate change: Analyzing the discourse. Cambridge Review of International Affairs, 21(4), 585-602. https://doi.org/10.1080/09557570802452920

Trombetta, M. J. (2011). Rethinking the securitization of the environment: Old beliefs, new insights. In T. Balzacq (Ed.), Securitization theory: How security problems emerge and dissolve (pp. 135-149). Routledge.

Wendt, A. (1999). Social theory of international politics. Cambridge University Press.

Yamada, T. (2017). Chikyuu kankyo mondai no anzenhoshoka no genkai to kanousei [The limits and possibilities of environmental securitization]. Kokusai Anzenhosho, 45(3), 18-34.

\section{About the Author}

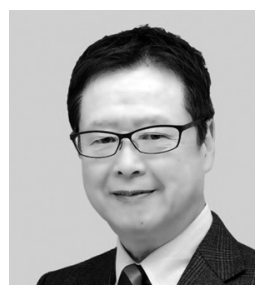

Takahiro Yamada is professor of international relations at the Graduate School of Environmental Studies of Nagoya University in Japan. Since 2017, he has also served as an associate member of the Science Council of Japan in political science. Since the early 1990s, Takahiro has contributed to international relations scholarship on a wide range of issues such as telecommunications, climate change, water resource management, and "business and human rights" with a particular focus on the diffusion of knowledge and norms in global governance. 